\title{
Study on the Training Mode of Network Security Practical Talent in Vocational and Technical College Based on Gamification and Leveling up
}

\author{
Shihua Liu", Zhanxiang Ye, Hao Zhang, Gang Wu \\ Department of Information Technology, Wenzhou Polytechnic, Wenzhou, China
}

Email address:

wzynetwork@wzvtc.edu.cn (Shihua Liu)

${ }^{*}$ Corresponding author

To cite this article:

Shihua Liu, Zhanxiang Ye, Hao Zhang, Gang Wu. Study on the Training Mode of Network Security Practical Talent in Vocational and Technical College Based on Gamification and Leveling up. International Journal of Education, Culture and Society.

Vol. 5, No. 4, 2020, pp. 79-84. doi: 10.11648/j.ijecs.20200504.13

Received: August 7, 2020; Accepted: August 20, 2020; Published: September 3, 2020

\begin{abstract}
In recent years, with the advancement of information and intelligence, the importance of network information security has become increasingly prominent, and the shortage of network security personnel has become increasingly serious. Vocational and Technical colleges mainly train practical network security talents, but network security requires a solid foundation of IT knowledge, a wide range of knowledge, part of the course learning boring, students have no motivation to learn. Therefore, Information Security and Management teaching and research section of Wenzhou Polytechnic company with the related security vendor, explore a training Mode of network Security practical talent in Vocational and Technical College based on gamification and leveling up. the basic knowledge learning task in traditional courses, the security service projects from companies and the CTF (Capture The Flag) network security competition contents are converted to corresponding grade leveling task, students can obtain corresponding experience points after complete the tasks. When students get enough experience points and meet the certain requirements, they will level up and get the skills' badges. After the required skills badges are all obtained, the student can trade-in course credits and scores or get the corresponding enterprise certification. In the actual teaching practice, the students respond positively to the gamification and gradation learning mode inspired by the clear goal, and gets better learning effect.
\end{abstract}

Keywords: Gamification, Leveling up, Vocational and Technical College, Network Security, Training of Practical Talents

\section{Introduction}

With the rapid development of new technologies and new forms of business such as mobile Internet, cloud computing, big data and artificial intelligence, the integration of information technology and economic and social fields is getting deeper, and the shortage of cyber space security personnel is emerging rapidly. Tencent Security released the "First half of 2017 Internet Security Report" shows that in recent years, China's university education training of information security professionals only more than 30,000 people, and the total demand for network security personnel is more than 700,000 , the gap as high as $95 \%$; Not only that, the report also pointed out that in the future, the information security talents of relevant industries in China will increase by 15,000 per year, and it is expected that the demand for relevant talents will grow to 1.4 million in 2020. Li Jianhua, dean of The School of Information Security Engineering, Shanghai Jiaotong University, believes that China's current security personnel training and the actual needs of the derailment, the lack of cybersecurity wizards and professionals found and training system and other problems. Non-trained "hackers" are often experienced in practice, but the current talent training system cannot ensure that these talents can be used for the country's cyber space security undertakings.

Demand for network security personnel is roughly divided into three categories, the first is research talents, this is the kind of top talents, most of them got the degree of master or doctor, the second is attacking talent, they are the wizards 
and geek, most of them engaged in vulnerability discovering, security researchers, as well as defensive talents, this kind of talents should have the sense of responsibility, and have fast learning ability and strong practice ability. This also is the key talent that trained in vocational and technical colleges. The network security personnel training at the higher vocational level is at the basic level of the talent echelon, and the demand is huge. Higher vocational colleges hope to combine industry and education to train practical network security personnel together with industry experts and university teachers. Wenzhou Polytechnic and Hangzhou Anheng Information Technology Co., LTD have signed a framework agreement from talent training to technical services, which explores a practical and feasible way in network security talent training.

Based on the practice of information security and management talent training of Wenzhou Polytechnic, the network security personnel training mode based on the gamification and leveling up are explored. from the talent training scheme, course gamification and leveling up transformation, to docking national vocational education $1+$ $\mathrm{X}$ authentication system and credit bank mechanism, teaching for university-enterprise cooperation projects in such aspects as talent cultivation has carried on the effective exploration. The training mode of practical network security personnel will provide a good reference and demonstration for the training of practical network security personnel in higher vocational colleges.

\section{The Application of Gamification in Education}

\subsection{Games Meet the Need for "Self-actualization"}

The maslow demand hierarchy theory suggests that human

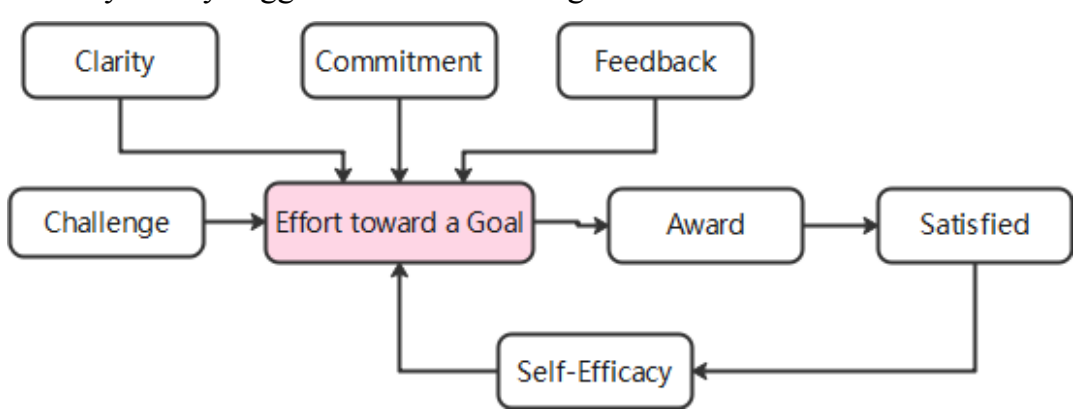

Figure 1. The diagram of Goal Setting Theory.

The first, Clarity, the clear objectives: when playing the game, you first know what the game task, with no clear goal, the player cannot know what to do and there is no specific behavior.

Second, Challenge, the appropriate target difficulty: if a task is very difficult, most people would give in, If a task seems simple, most people get bored. The goal is the player can achieve through hard work, only then can stimulate the player's sense of accomplishment, attract them to do the task.

Third, appropriate feedback: after the game, players need to demand is divided into five levels from low to high, and that is: physical needs, security needs, love and belonging, respect for demand and self-realization requirements. With low demand, high demand will be the main driver of people. And only a few people can achieve self-fulfillment in reality. Contemporary college students, especially from large and medium-sized cities, have a common living material condition, and their physical, safety, love and ownership requirements are generally satisfied. Whether the demand for respect is satisfied depends largely on whether it will succeed in learning If students are qualified for their learning tasks, he will be able to achieve a higher sense of accomplishment between his classmates and feel respected. Conversely, it will be lost, even inferior. In order to get more self-respect, you can only seek other satisfaction. So, these people can find the sense of self-fulfillment through the game. In the game, the player may be rich or beautiful, or the technical is good, which makes them is respected. It can be found in the game but missed in reality. For example, a "bad" child is not good at learning. In real life, he has no sense of accomplishment and is not respected. In the world of games, he can be exposed to the list and worshiped by other players, thereby achieving a sense of accomplishment and achieving "self-realization".

\subsection{Goal Setting Theory}

Why the game is so attractive, and people have done a lot of research and exploration, based on the Goal setting theory: the goal is the purpose of a person's attempt to accomplish it. The goal is the most direct motivation for behavior, and setting the right target makes it possible for people to achieve the desired achievement of the goal, thereby having a strong incentive for people. It is important to focus and set the right target as important as possible [1].

The goal setting theory and the key items setting in the game is as follows:

get rewards or feedback to tell players how to performance. If the player is satisfied with the reward, the player will proceed to the next mission.

According to "operational conditioning," feedback (rewards) tells the player what to do next. When a player gets a reward for completing a task, he tends to complete more such tasks. Feedback can also enhance the player's sense of accomplishment. But the premise is, the reward is meaningful to the player.

So when players are willing to do repetitive work at odd 
levels in the game, "clear goals" and "meaningful rewards" play a big role.

\subsection{The Application of Gamification in Education}

In the field of education, participation is regarded as a valuable indicator to measure students' academic performance [2-4]. Dedicated students are attracted to their work, persist in their academic activities despite the challenges and obstacles, and take evident pleasure in completing their work. Therefore, different approaches to cultivating student participation have been developed and evaluated. The most successful of these methods are number games because, when combined with effective pedagogy [5-7], they can potentially create engaging learning experiences for students.

Gamification refers to the "use of game design elements in non-game environments" [8-9]. Gamification refers to the application of design elements of video games to non-game Settings in traditional discipline education and classroom teaching in order to attract participants and encourage desired behaviors. Gamification has always been an effective way to engage users. It has been recognized as a promising technology that can increase students' participation in learning with a positive impact. A common model of gamification is to equate activities in a non-game environment with points and receive external rewards when a specified point threshold is reached. An important problem with this gamification is that it reduces the user's internal motivation for the activity because it replaces internal motivation with external motivation. However, if game design elements can be made meaningful to the user through information, internal motivation can be improved, as there is less need to emphasize external rewards. Nicholson et al. introduce the concept of meaningful gamification by exploring the user-centered theory behind organizational integration theory, situational relevance, situational inspiration, general learning design and player-generated content [10].

Hamari et al. reviewed their empirical research on gamification. Through the definition of gamification and the discussion of motivation revelation, a framework for investigating the effects of gamification is established. They point out that gamification has brought about positive effects, however, these effects depend largely on the context in which gamification is implemented and the users who use it [11].

For gamification to be useful in schools, we must have a better understanding of what gamification is, how it works, and why it might be useful. Lee et al. understood and read these questions and explored the potential benefits and defects of gamification [12]. Seaborn $\mathrm{K}$ et al. discussed the advantages and disadvantages of gamification and proved its effectiveness as a tool to motivate and attract users in a non-entertainment environment through empirical research [13].

Ibanez et al. analyzed the implementation effect of gamification in $\mathrm{C}$ programming course. Through the collection and analysis of data including logs, questionnaires, pre - and post-test, it is found that game-based learning activities have a positive impact on students' participation and a moderate improvement in learning outcomes [14].

Huang Jin in gaming course teaching, the construction of appraisal system of the game, game elements, such as introducing experience points and level-up through the informationization teaching platform, design based on the game thinking, lessons before class, after class, curriculum grade evaluation system, for the gaming thinking in the teaching evaluation provides a practical solution [15].

Aparicio $\mathrm{M}$ et al. propose a theoretical framework to identify the determinants of successful Massive open online courses (MOOCs), and empirically measure these factors in a real MOOC context. They put forward the role of gamification and suggest that, together with information system (IS) theory, gamification proved to play a crucial role in the success of MOOCs [16].

As for the cultivation of network security talents, CTF (Capture The Flag) competition, as a specific game-based learning environment, is widely used in many colleges and universities. The combination of CTF competition and security courses can successfully improve students' hands-on skills and learning enthusiasm $[17,18]$.

\section{Design of the Gaming Training System of Network Security Practical Talents in Higher Vocational Colleges}

The key to realize the training of gaming and level-up talents lies in the decomposition of knowledge points according to skill requirements, and the completion of course learning tasks or project task module construction according to knowledge requirements. Learning tasks or real projects serve as a resource base for students' fragmented learning. Each task corresponds to the corresponding credits, and students can get the corresponding credits for each task they complete. Accumulate the points and get the Badges corresponding to the skill points. Accumulate the Badges and get the credits corresponding to the course assessment. In the end, skills Badges are used as the evaluation criteria for the trained talents, and students can obtain the corresponding professional engineer certification if they accumulate certain Badges. as illustrated in Figure 2.

Gaming leveling of talent training implementation can use any support task allocation, experience points calculation, level, badges, a certificate issued by the online learning management platform (for short: X platform), the platform can support the gaming of knowledge into specific courses and gaming learning tasks. Publish the points learning task, CTF competition task and real project task of the safety course, and formulate the corresponding credit mutual recognition mechanism. All the learning tasks and real project tasks are published on X platform. Students can choose to participate in the bidding according to their own situation, and they can see the improvement of their score level and the acquisition of badges in real time on the platform. This is not only conducive to students' personalized learning, but also more reasonable with the current college credit program to match. 


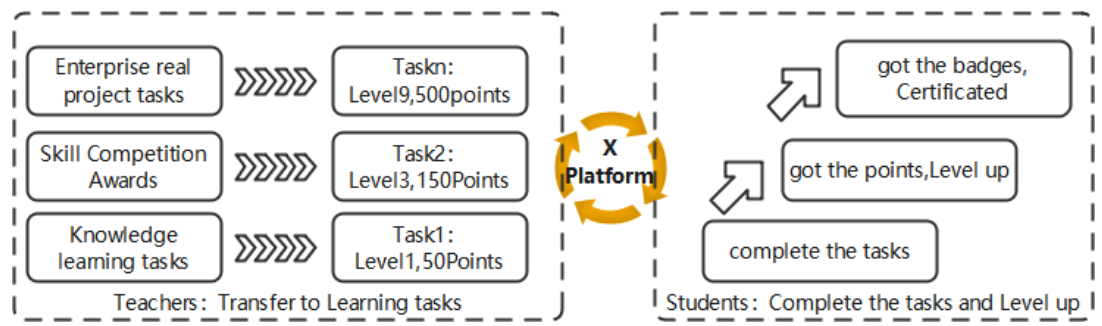

Figure 2. Talent training mode based on gamification and leveling up.

\section{The Implementation Case of Gamification and Leveling up}

Taking the course "Log Collection and Analysis" as an example, the course construction under the new talent training mode includes curriculum standard development, teaching material construction and teaching resource database construction. According to the requirements of game training, the course content is divided into task packages, and according to the difficulty level of each task package, the corresponding points and difficulty levels are set. Finally, a student evaluation system is developed to evaluate students who have completed the corresponding tasks. Corresponding skill badges will be awarded according to the scores, and course credits will be given according to the accumulation of skill badges. According to the acquisition of course credits, enterprises can also be connected with the corresponding certification. For example, the course credits of "Log Collection and Analysis" can be regarded as one of the certification contents of network security emergency response engineers.

The training level course system of fragmented tasks is shown in Figure 3. Among them, project tasks can be leveling-up tasks for the transformation of knowledge and skill points of school basic courses, such as the module "use of $\log$ analysis tools". As the first-level task, the number of points is 50. It can also be a real job required for an enterprise's local service, such as a log emergency forensics project, which can be a level 5 task and earn 250 points for completion; For Apache log analysis and other task modules, based on the actual teaching situation, simulated project tasks or real project requirements of government and enterprise can be used as leveling-up tasks, or CTF contest questions can be used as problem solving tasks.

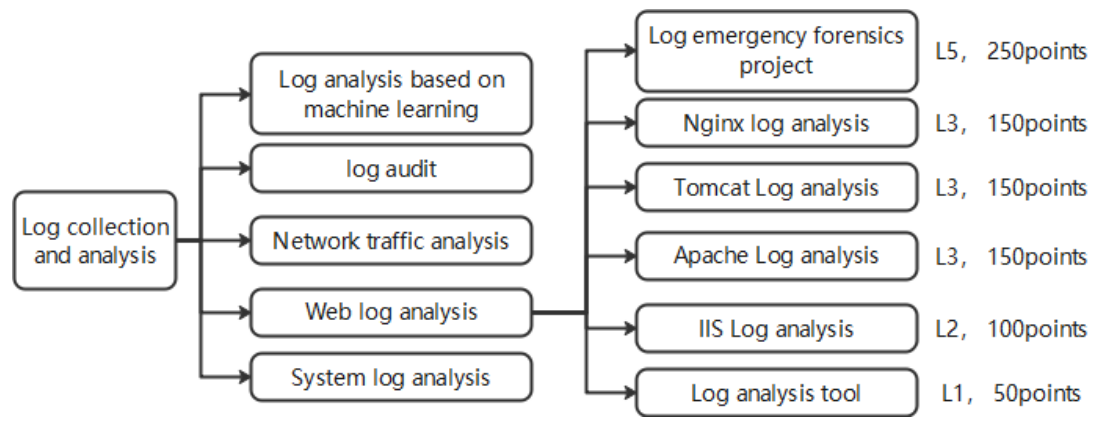

Figure 3. Construction of a fragmented task-level course system.

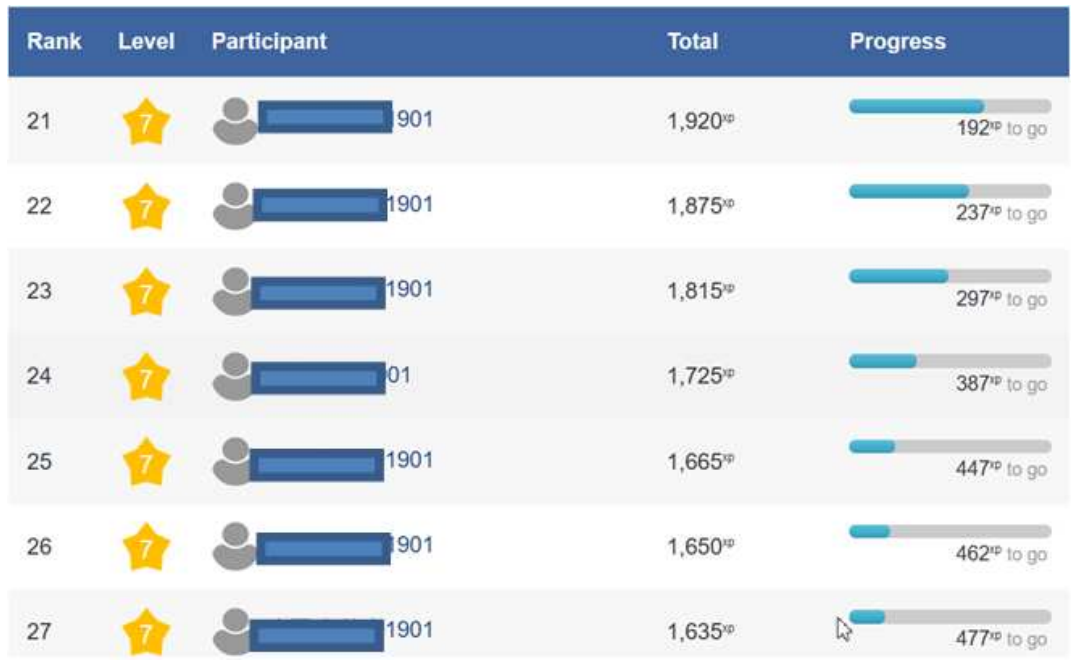

Figure 4. Rank list of Students' level and experience points. 
Students get the corresponding experience points or credits by completing the tasks set in the course. When the credits reach a certain score, the user level will be promoted automatically. As shown in the figure above, students can check their scores and grades through the platform in real time, and can check their current ranking in the class, which effectively promotes students' learning enthusiasm and increases the incentive effect of gamification.

\section{Conclusion}

This paper starts from the analysis of the attraction of games to people, summarizes the application of gamification in current education and teaching, and elaborates the network security practical personnel training mode adopted by the information security and management major of Wenzhou Polytechnic.

The key to realize game-based training of talents lies in the decomposition of knowledge points according to skill requirements, and the completion of course learning tasks or project task module construction according to knowledge requirements. On the basis of introducing the design of the overall talent training system, this paper takes the concrete implementation of a course as an example and describes the specific details of the course gamification. The diversified composition of learning level-up tasks is conducive to the docking between students and social needs, to maintain students' interest in learning, and to enhance their sense of achievement in learning.

\section{Acknowledgements}

This paper is supported by the following fund projects, in no particular order:

Major Teaching Reform Project of Wenzhou Polytechnic: "The exploration of the "Wenzhou Polytechnic mode" for the Gamification cultivation of practical network security talents cooperate with Government and enterprise cooperation" (No. WZYZD201807)

The first batch of teaching reform research Projects in the 13th Five-Year Plan of Higher Education in Zhejiang Province, the Technical service Center jointly built by government, enterprise and college, and the construction of an ecological circle for the integration of industry and education, taking the application-oriented personnel training of higher vocational Cybersecurity as an example (No. jg20180583)

Cooperation Project of School-Enterprise and Enterprise for Visiting Engineers of Higher School in Zhejiang Province: "Research on the Training Mode of Network Security Actual Personnel in Higher Vocational School-Enterprise Cooperation of Project Training Level "(No. FG2018064)

Major Teaching Reform Project of Wenzhou Polytechnic: The construction and research of the cyber space security training platform based on the integration of industry and education from the perspective of "Internet +" (No. WZYZD201806).

\section{References}

[1] Locke, E. A.. Toward a theory of task motivation and incentives. Organizational behavior and human performance, 19683 (2), 157-189.

[2] S. De Freitas, "Learning in immersive worlds: A review of game based learning. Prepared for the JISC e-Learning Programme," JISC eLearning Innovation, vol. 3.3, pp. 1-73, JISC, Oct. 2006.

[3] V. Hancock, F. Betts, "Back to the future: Preparing learners for academia success in 2004," Learning \& Leading with Technology, vol. 29, no. 7, pp. 1-14, April 2002.

[4] J. P. Portelli, B. McMahon, "Engagement for what? Beyond popular discourses of student engagement." Leadership and Policy in Schools, vol. 3, no. 1, pp. 59-76, Mar. 2004.

[5] T. M. Connolly, E. A. Boyle, E. MacArthur, Y. Hainey, J. M. Boyle, "A systematic literature review of empirical evidence on computer games and serious games," Computers \& Education, vol. 59, no. 2, pp. 661-686, 2012.

[6] J. P. Gee, What Video Games Have to Teach Us About Learning and Literacy, p. 256, New York, Palgrave Macmillan, 2003.

[7] M. Prensky, Digital Game-Based Learning, USA, McGraw-Hill, 2001.

[8] Deterding, S., Dixon, D., Khaled, R., \& Nacke, L.. From game design elements to gamefulness: Defining "Gamification". Proceedings from MindTrek '11. Tampere, Finland: ACM. 2011.

[9] Sgueo G. Gamification [M] // The Palgrave Encyclopedia of Interest Groups, Lobbying and Public Affairs. 2020.

[10] Nicholson S. A User-Centered Theoretical Framework for Meaningful Gamification [C]// Games+Learning+Society 8.0, Madison, WI. 2012.

[11] Hamari J, Koivisto J, Sarsa H. Does Gamification Work? -- A Literature Review of Empirical Studies on Gamification [C]// Hawaii International Conference on System Sciences. IEEE, 2014.

[12] Lee J J, Hammer J. Gamification in Education: What, How, Why Bother? [J]. Academic Exchange Quarterly, 2011, 15 (2): 1-5.

[13] Seaborn K, Fels D. Gamification in theory and action: A survey [J]. International Journal of Human - Computer Studies, 2015, 74: 14-31.

[14] Ibanez M B, Di-Serio A, Delgado-Kloos C. Gamification for Engaging Computer Science Students in Learning Activities: A Case Study [J]. Learning Technologies IEEE Transactions on, 2014, 7 (3): 291-301.

[15] Huang Jin. Curriculum Assessment Construction based on Gamification -- A Case study of Database Application Foundation in Higher Vocational Education [J]. Education Modernization, 2019.

[16] Aparicio M, Oliveira T, Bacao F, et al. Gamification: A Key Determinant of Massive Open Online Course (MOOC) Success [J]. Information \& Management, 2019, 56 (1): 39-54. 
[17] Raghu Raman, Sherin Sunny, Vipin Pavithran, Krishnasree Achuthan,"Framework for Evaluating Capture The Flag (CTF) security competitions", International Conference for Convergence of Technology -2014.
[18] Jason Flod, Mark Denihan, Anthony Keane, Fredrick Mtenzi, "Black Hat Training of White Hat Resources: The Future of Security is Gaming", The 7th International Conference for Internet Technology and Secured Transactions (ICITST-2012). 